\title{
ERGONOMICS IN PRACTICE AND ITS INFLUENCE ON EMPLOYEES" PERFORMANCE
}

The article deals with the human performance and the factors that affect job performance. During the performance of work a person is exposed to risk factors which to some extent adversely affect his health. It is necessary to note that two views of the position of man in the process currently prevail in the company. The first one, promoted by particular employers, puts the emphasis on performance increase of workers and productivity growth. The second one view is supported by employees and emphasizes the need for safety of a man and health at work. The aim of ergonomics is currently referred to harmonise these views.

Keywords: Workload, performance, work performance, performance curve.

\section{Introduction}

Work is an essential and, therefore, the dominant activity in the life of every person. An employer has to create the optimal working conditions for an employee to be able to use their performance-related capacity fully. The results which the keeping of the ergonomic rules in an enterprise brings can be divided into the economic ones, important for the employer and the health keeping ones, important for the employee. A man spends an essential part of their life in a work activity which has formed them during the whole evolution. Therefore, we cannot overlook work activity and its effect on a person because it has progressive importance in human development and it is the factor of mental and physical functions improvement [1 and 2].

More and more difficult combination of the relationship between a man, a working means and an object of work has been culminating recently. Human working activity has been expanding but, at the same time, the working conditions and the demands on a workman have been changing. Nowadays the development of science and technology extends into the structure of productive forces of society. It also influences the relation of a human being to work and their working conditions and thus affects their lifestyle. The demands on development of motor abilities and experience have been decreasing; the importance of sensory experience, theoretical and intellectual knowledge has been increasing. The changes in human behaviour are arising as a consequence. These are the changes of a technical character which influence the working environment as well as the changes in human behaviour. The changes may occur in positive or negative reactions influencing the satisfaction rate, the level of the spent effort and health risks for workmen while performing [3].

\section{Current problems in ergonomics}

The problems which are related to their influence on the employee emerge simultaneously with the changes of working conditions. Each change in working and technological procedures leads to the changes in work conditions and demands imposed on a person. In most cases we do not pay much attention to these consequences to the employees. We are only interested in them when they have an accident, illness or a negative influence on the employee is visible.

Often there is a conflict of opinions as to the means of production affect humans. On the one hand it can be argued that they facilitate working, on the other hand, may adversely affect the employee performing work [4 and 5]. Also, you can still watch the signs of factors unfavourable for working conditions, such as air pollution, improper spatial solution of workplaces, chemical pollutants, and stressful situations and so on.

It is appropriate to think about the fact that technical progress, which should serve man, often turns against them. The progress of science and technology often facilitates the work of staff outside the work activities but sometimes it is at the cost of human health. It is not only about the damage to health of the employee being influenced by risk factors, such as occupational

\footnotetext{
* Luboslav Dulina, Miroslava Bartanusova

Department of Industrial Engineering, Mechanical Faculty, University of Zilina, Slovakia

E-mail: luboslav.dulina@fstroj.uniza.sk
} 
disease or accidents at work. It may also be the effect of those factors, the importance of which comes to the fore only in a combination with certain conditions of work. They may initially manifest themselves by dissatisfaction, incapacity to work or other forms, which can upset the balance between the claims that are made on the employee and their options to deal with them [6,7 and 8].

\section{Workload and work performance}

As Skrehot stated [9] the workload is a set of external conditions, requirements and circumstances of the particular job system affecting physiological and psychological state of man. It can therefore be argued that each work activity represents a challenge for the organism. The size of the application of the load depends on several factors [9]: the readiness and capability of the employee to perform the task, from the very nature of the task and the conditions under which the performance of the task takes place. With excessive workload not only the size of physical force, but also the human psyche are worsen.

It can be argued that every individual has a certain performance. Performance is understood as a group of attributes and skills that form the precondition for the proper accomplishment of tasks [5 and 10]. Performance can be characterized as a person's ability to bring power per unit of time. The work output we produce is only a part of the overall performance, which we are able to perform.

Work performance is the result of a purposeful activity that takes place over time under certain conditions [5 and 11]. When we think of how much power is to be submitted during work activities and, for example, in sports, we can perceive a significant difference. During the sport, naturally, we try to give out our maximum and give the best performance. This is not at work. Here, it is particularly important that staff is able to serve the longterm stable performance. We can, therefore, conclude that job performance does not reflect the effort with which the employee performs the activity, or how much of their power reserves has been used. The term work performance can present a concrete result of the work that is done under certain conditions and for a certain time unit.

People bring different power in identical situations. Also, an individual performance in a relatively short time intervals may vary. Due to the mentioned considerations and the fact that every exercise cannot be measured by energy loss per unit time, it is more preferable to consider performance.

As it has already been mentioned a man gives only a certain proportion of their output when working. It is called the performance-related standby where the man leaves the rest (so-called power reserve) mostly to non-work activities [11]. For the activities in the working processes in most cases it is not necessary to use the full performance, with which we dispose, hence the reserve. Natural biological barriers and regulatory mechanisms prevent it. Exactly these regulate the man's output and for a particular employee they ensure an average and for him the most satisfactory output to be maintained.

\subsection{The factors influencing work performance}

Almost all the operating results are achieved through company employees. Through it, i.e. how they consistently do their jobs, they contribute greatly to the achievements of business objectives, ensuring the competitiveness of the company and increase performance.

As already mentioned, the boundaries of human performance are limited by opportunities and the limitations of power reserve. Subjective factors play an important role here and they represent individual human capacity to use its throughput capacity to complete the required work results [12]. How much a person actually makes the use of the power capacity also depends on the interest to fulfil and achieve the desired performance.

Objective performance conditions include external circumstances in which performance takes place. These are the factors which are extraneous to the employee and the employee cannot affect them either [12]. The mentioned factors (Fig. 1), however, affect their job performance and, therefore, it is necessary to be aware of the degree of their impact on the employee and to examine them in detail.

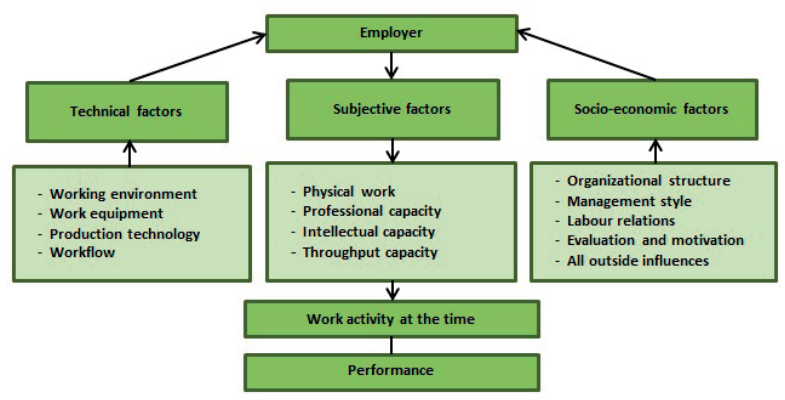

Fig. 1 Factors influencing employee's work performance

Based on the knowledge we have of psychology, physiology, anthropometry, hygiene and other areas that make up the knowledge base of ergonomics, the standardized values of the factors in the working environment have been defined.

According to Gilbertova and Matousek [13] and Kovac [4] the performance capacity of a person is affected by the following factors:

a) Sensorimotor capacity - primarily a function of vision and hearing belong here. Capacity of sight is given by:

- Visual acuity - the ability for the eye to distinguish objects and their details at a distance. It is possible to express it by the angular size (about $5-6$ minutes of arc) or the so-called acuity is determined, which is the ability of 
the eye to identify the two closest points lying as two separate objects. The ability of the sharp perception of the environment by means of vision is determined by the size of the viewing angle which can be measured by perimeter. Optimal field of view in the design is a $20^{\circ}$, normally $60^{\circ}, 120^{\circ}$ and functional up to $220^{\circ}$ [14].

- Spatial vision - i. e. stereoscopic binocular vision, it is the ability to determine correctly the distance of objects in space, in both horizontal and vertical directions.

- Eye accommodation - it is an adaptation of the eye, the change in optical power due to the interest in seeing objects at different distances sharply.

- Colour vision - it is the ability to perceive the different colours of light in the visible radiation in the wavelength range $380-760 \mathrm{~nm}$. According to studies, healthy human eye is able to distinguish between about 130 to 150 colours in the range $400-700 \mathrm{~nm}$. From the point of view of the field of vision, the level of sufficient distinctiveness of colour is in the horizontal plane of the eye $30^{\circ}-60^{\circ}$ on both sides and $30^{\circ}$ above the axis and $70^{\circ}-80^{\circ}$ below the axis of vision in the vertical plane [13].

- Adaptation of the eye - by the eye adapting to the changes of lighting conditions. The requirements for the rapid adaptation of the eye are associated with uniform lighting of workplaces and observing the correct ratio of brightness between the workplace and the environment.

- Reaction of the hearing to the sound - it is the ability of the organ of hearing to perceive sound stimuli from the environment. For a man the sound pressure level and frequency of the sound are important. Hearing shows the greatest sensitivity in about $1000 \mathrm{~Hz}$. The time interval for a man needed to realize a sound is 0.1 to 0.15 , and its value depends mainly on human attention [4].

b) Mental capacity - incorporates psychic abilities (sensorimotor, intellectual, and cognitive), motivation, will and others. Its basis is the intellectual level of a person. The intelligence quotient, which may be obtained by tests and psychological methods, is used to find it out. Unlike sensory capacity, which is determined by the appropriate physiological analyzer and is expressed in physical units, the setting of mental capacity limits is very complicated and the result is only approximate [4].

c) Human adaptation to working conditions - it is the ability of humans to adapt to the working conditions and resulting changes. The activity that one must make to overcome the resulting changes is crucial when adapting. It is affected by [4, 14 and 15].

- The type and contents of working activity by which is meant the nature of work tasks and operations, the technology used, machinery, equipment, and material.
- The risks associated with work - harmful working environment, working with hazardous machinery.

- The work and rest - the system of breaks during the shift, unevenly distributed workload and others.

- Social climate in the workplace - interpersonal relationships, level of social support.

\subsection{Performance curve}

Readiness of a man to the work performance during the day varies from person to person. Physiological readiness to bring power is the highest in the morning and decreases gradually during the day. It is, therefore, recommended not to burden a person with strenuous work activity in the afternoon and in the evening (except for Shift-plus operation). For duty cycle control it is necessary to have the basic understanding of the fact that there is a fluctuation in human performance during the workday, 24-hour daily cycle, week, or year [11, 16 and 17].

Annual fluctuations in performance - Fig. 2 shows the annual variation of human performance during the year, while the $F$ curve illustrates the physical performance and the $\mathrm{P}$ curve the course of mental performance.

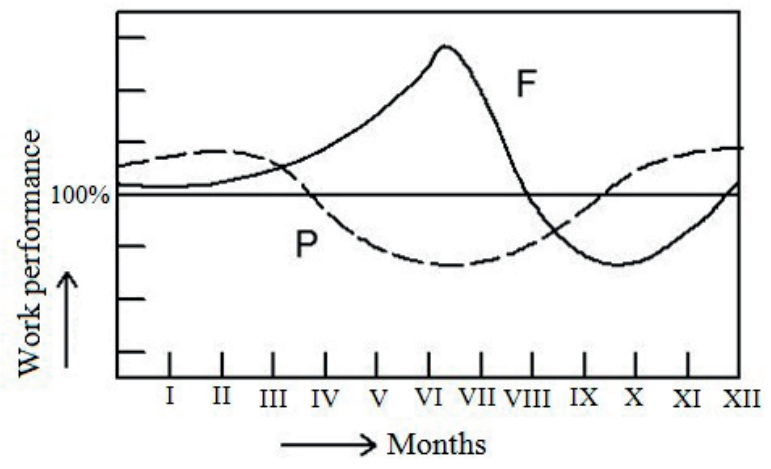

Fig. 2 Annual variation in performance [11]

Weekly variations in performance - performance during the week changes (Fig. 3). On Monday the power is the smallest, due to the decrease in dynamic stereotypes and reduced concentration after the weekend. At the end of the week our performance declines, not due to physical fatigue, but due to psychological factors (psychological preparation before the weekend, decreased concentration). 


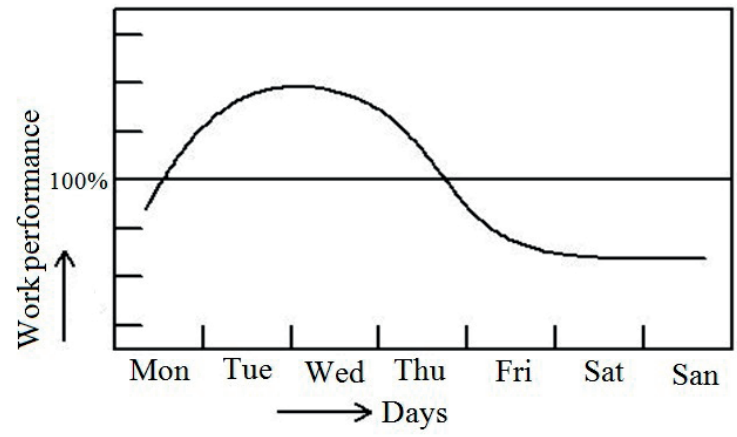

Fig. 3 Weekly variations in performance [11]

Daily fluctuations in performance - the human organism alternately varies during the day and night from the work (power) to the rest (recovery). At the same time physiological functions change (change in blood pressure, body temperature, skin elasticity) as well as mental functions (attention, reaction time). The performance decreases over time in proportion to the intensity and difficulty of work (Fig. 4).

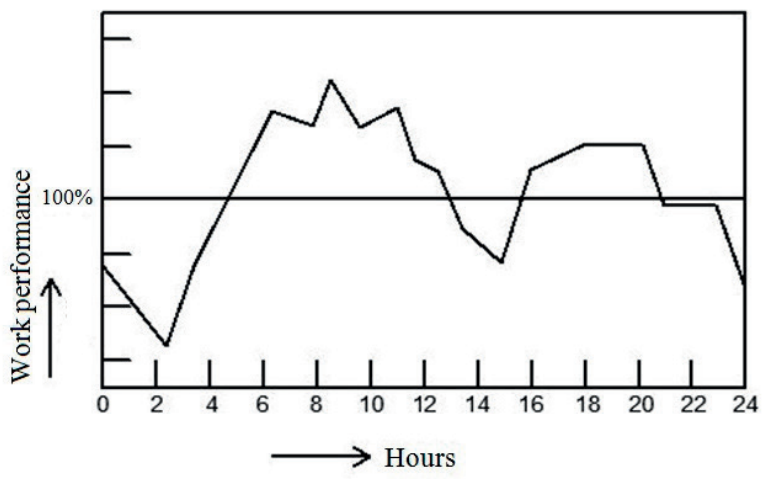

Fig. 4 Daily fluctuations in performance [11]

Fluctuations in performance during the shift - Fig. 5 shows the performance of each hour of a work shift. Due to the type of work and individual abilities of a man the length and the duration of the different phases is different.

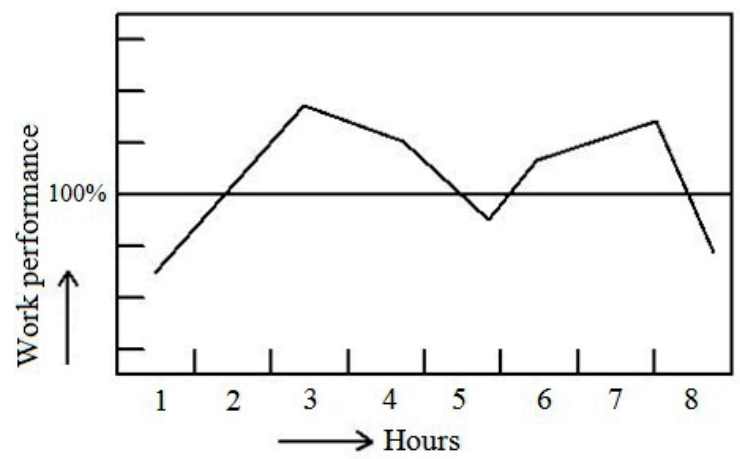

Fig. 5 Variation in performance during the shift [11]

\section{Assessment and control of work performance}

To assess and evaluate the employee's work performance, i.e. their capability to perform the required work performance, is an important basis for improving the functioning of enterprises, thus increasing their overall efficiency.

Man's work performance can be assessed using the following criteria [12]:

- The length of time needed to carry out the activity.

- The maximum time reserved for that activity.

- The amount of work performed during a certain time.

- The amount of work done regardless of the performance and time.

These criteria are not sufficient to evaluate the job performance and it is needed to supplement them by the additional and more detailed criteria such as performance stability over time, the occurrence and frequency of erroneous decisions, quality of work, accident and more.

Under the conditions that the requirements for a job are met, the employee's performance at work might be regulated as follows:

- Duration of work (prolongation or shortening of working hours, alternating time intervals designed to work and relaxation).

- Speed with which the work is performed and the degree of work pace (shortening the time appointed for a rest or designated for a work performance).

- The amount of work done and power expanded (the weight of the load to be handled, the number of manipulated loads).

In case that we would like to regulate the work output it is required from an ergonomic point of view to know the following indicators:

- Thresholds which determine the functional performance values of a healthy organism.

- The interaction of those features that is important for a job performance.

- Factors that may limit the boundaries and hence the performance of the employee.

From my own experience and observation it can be stated that a work performance may not be equally troublesome for different people. The effort you feel as an individual for a specific individual exercise may also vary depending on fatigue, disease, mental status, number of breaks, and many other factors. Between the throughput capacity, which we have and the work performance that has been produced, we also have the already mentioned power reserve. Just the mentioned power reserve helps us cope well with such situations which are considerably of higher demands on our work performance. Despite the reserve which we 
have, the increased or decreased performance in the long term can cause significant changes in our bodies.

\section{Employment impact on humans}

At work, which is defined by reserved working conditions, requiring the occupation as such, work environment or work equipment, the fact that human performance is limited comes significantly to the fore. The employer should assess the intensity of work load on the body of the employee. The employer also should focus on how the harmful effects influence the performance and, in particular, their health. The employer is obliged to think of legislation, the task of which is to protect the health of the employee. The factors that affect job performance interact with each other, have a different degree of severity and the degree may, of course, vary depending on the time and the current conditions. It is necessary to note that the factors that affect the performance may be changed in combination with other factors and they may be positive or negative. The employer should be aware of it and in some cases, accept the change of the employee's performance, thus lower demands may cause more problems for the employee as might be expected.

\section{Human impact on work activity}

With the development of science and technology machine performance has also increased. Businesses are trying to achieve the best results and highest profits. With the advantages that a new technique and technology bring, the employee's performance becomes the weakest link in the production process. Even greater demands are placed on staff in order to utilize their maximum possibilities as well as the maximum use of the machine. From a health perspective, it is possible for a short time, but only if it is followed by a sufficiently long rest. The employer should deal with the contradiction between limited human performance and unlimited possibilities of modern technology.

\section{Acknowledgement}

The article was created within the research project VEGA No. 1/0701/12 Research on the use of low-cost automation and artificial intelligence in the process of stereoscopic recording.

\section{References}

[1] HLADKY, A.: Ergonomic Increases Motivation and Performance. Ceska ergonomicka spolecnost. Human Resources Management, 2007, vol. III., No. 6, 10-12. ISSN 1801-4690

[2] STEFANIK, A., GRZNAR, P., MICIETA, B.: Tools for Continual Process Improvement - Simulation and Benchmarking. Annals of DAAAM for $2003 \&$ Proc. of the $14^{\text {th }}$ Intern. DAAAM Symposium: Intelligent manufacturing \& automation: Focus on reconstruction and development, 2003, 443-444, ISBN: 978-3-901509-34-6

[3] GASO, M., MICIETA, B.: Application of Stereoscopic Records in Ergonomics. $5^{\text {th }}$ Intern. Ergonomics Conference: ERGONOMICS 2013, Zagreb: Croatian Ergonomics Society, 2013, 223-228. ISSN 1848-9699

[4] KOVAC, J., SZOMBATHYOVA, E.: Impact of Selected Ergonomic Factors on Human Performance at Work. Inovacne centrum automobilovej vyroby. Transfer inovacii, No. 8, 2005, 76-77, ISBN 80-7093-6

[5] KUBANI, V.: Psychology of Work. PU Presov : FHPV, 2005, 81 p., ISBN 80-8068-331-X

[6] HATIAR, K.: Modern ergonomics. Productivity and Innovations, vol. IX, No. 6, 2008, 22-24, ISSN 1335-5961

[7] KOVAC, J., SZOMBATHYOVA, E.: Ergonomics. TU Kosice: SjF : Edicia studijnej literatury Kosice, 2010, 122 p., ISBN 978-80-5530538-7

[8] VRABlOVA, L., GREGOR, M.: Company in Crisis. Communications - Scientific Letters of the University of Zilina, vol. 13, No. 4, 2011, 78-81, ISSN 1335-4205

[9] SKREHOT, P., MAREK, J.: Basics of Applied Ergonomics: Safe Company. Praha: VUBP, 2009, 118 p., ISBN 978-80-86973-58-6

[10] KRAlOVA, Z., KRAJCOVIC, M.: Variance in a Second Language Production Quality. Communications - Scientific Letters of the University of Zilina, vol. 11, No, 4, 2009, 15-23, ISSN 1335-4205

[11] LORKO, M.: Ergonomics in Manufacturing. Technicka univerzita, 2001, 105 p., ISBN 80-7099-692-7

[12] BABELOVA, Z.: Impact of Employee Performance to Business Performance. 2004, 323 p., Brno : VUT Juniorstav, ISBN 80-2142934-8

[13] GILBERTOVA, S., MATOUSEK, O.: Ergonomics. Optimization of Human Activity. Grada Publishing : Praha, 2002,239 p., ISBN 80-247-0226-6

[14] CHUNDELA, L.: Ergonomics. CVUT Praha, 2000, 55 -57, ISBN 80-01-02301-X 
[15] PALAJOVA, S., GREGOR, M.: Simulation Metamodeling of Manufacturing Processes. Communications - Scientific Letters of the University of Zilina, vol. 13, No. 4, 2011, 51- 54, ISSN 1335-4205

[16] KRAJCOVIC, M., BULEJ, V., SAPIETOVA, A., KURIC, I.: Intelligent Manufacturing Systems in Concept of Digital Factory. Communications - Scientific Letters of the University of Zilina, vol. 15, No. 2, 2013. 77-87, ISSN 1335-4205

[1] GREGOR, M., STEFANIK, A., HROMADA, J.: Lean Manufacturing Systems Optimisation Supported by Metamodelling. IFIP Intern. Federation for Information Processing, vol. 257, 2008, ISSN 1571-5736. 